\title{
Association between hours worked in paid employment and diet quality, frequency of eating out and consuming takeaways in the UK
}

\author{
Lucy Sam ${ }^{1, *}$, Tony Craig ${ }^{2}$, Graham W Horgan ${ }^{3}$ and Jennie I Macdiarmid ${ }^{1}$ \\ ${ }^{1}$ The Rowett Institute, University of Aberdeen, Aberdeen AB25 2ZD, UK: ${ }^{2}$ The James Hutton Institute, Aberdeen, UK: \\ ${ }^{3}$ Biomathematics \& Statistics Scotland, Aberdeen, UK
}

Submitted 7 January 2019: Final revision received 4 May 2019: Accepted 17 May 2019: First published online 13 August 2019

\begin{abstract}
Objective: To examine associations between hours worked and diet quality, frequency of eating out and consuming takeaways.

Design: Data were taken from the National Diet and Nutrition Survey (2008-2014). Associations between hours worked in paid employment and diet quality, assessed using the Diet Quality Index (DQI) and selected foods and nutrients, were tested using linear regression models. Associations between hours worked and frequency of eating out and consuming takeaways were tested using ordinal logistic regression models. All models were adjusted for sex, age, equivalised household income, household composition and household food role.

Setting: UK.

Participants: Adults ( $n$ 2154) aged 19-64 years in employment.

Results: Mean (95\% CI) hours worked per week was 36.1 (35.6, 36.6) and mean DQI score was $41.9(41.2,42.5) \%$. Hours worked was not associated with DQI score, frequency of eating out or consuming takeaways. Hours worked was positively associated with consuming red meat, processed meat and alcohol intake. Adults working more hours had lower intake of fibre but higher total fat and saturated fat intakes if they lived in households with children.

Conclusions: Working hours may not be the main factor driving poor-quality diets among this sample of UK adults in employment. Focusing on consumption of foods prepared outside the household may not be the most efficient way to improve diet quality as effort is needed at all levels. Although it is unclear what is driving the differences in nutrient intakes according to household composition, they are important to consider when developing interventions to improve healthy eating.
\end{abstract}

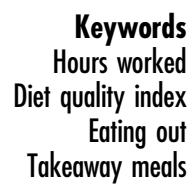

Healthy diets are essential in the prevention of diet-related chronic diseases ${ }^{(1-3)}$, which makes it important to identify drivers of unhealthy food choices. A key factor underpinning food choice is time ${ }^{(4,5)}$ and issues pertaining to a lack of time, time constraints and perceived time pressure appear particularly pertinent among adults in employment ${ }^{(6-8)}$. A lack of time is commonly reported as a barrier to food preparation ${ }^{(9,10)}$ that may result in greater use of convenience food practices, as several studies have linked time-related issues to increased likelihood of eating out at restaurants, purchasing fast-food and takeaway meals, and consuming processed ready-meals ${ }^{(10-13)}$. This could have negative implications for overall diet quality and health as increased consumption of meals prepared away from home has been associated with diets with higher intakes of energy, fat and $\mathrm{Na}$, and lower intakes of fruits, vegetables and micronutrients including vitamin $\mathrm{C}, \mathrm{Ca}$ and $\mathrm{Fe}$, as well as higher BMI, weight gain and insulin resistance ${ }^{(14-20)}$. Furthermore, greater reliance on convenience processed foods may inversely correlate with the likeliness to prepare food at home, which has typically been linked to better dietary outcomes. This was found in a US study where compared with participants spending over $2 \mathrm{~h} / \mathrm{d}$ on food preparation, those who spent less than $1 \mathrm{~h}$ had greater expenditure on foods prepared away from home and increased frequency of fast-food consumption ${ }^{(21)}$. That study also found positive correlations between time spent on home-food preparation and frequency of consuming 
healthier food items such as fruits, vegetables and salads $^{(21)}$. Several other cross-sectional US studies report similar findings, with greater frequency of home cooking being associated with increased tendency to meet recommendations for fruits, vegetables, whole grains, fat and $\mathrm{Ca}^{(9)}$, and with lower energy, fat and sugar intakes ${ }^{(22)}$ as well as a lower risk of obesity ${ }^{(23)}$

However, home-made meals are not necessarily always healthier in terms of nutritional content. For example, a cross-sectional UK study found main meals created using recipes from books published by celebrity chefs to contain significantly more energy, protein, fat and saturated fat and significantly less fibre per portion than the ready meals sold by three major UK supermarkets ${ }^{(24)}$. The nutritional quality of home-made meals may also be dependent on other factors such as higher socio-economic status and more positive attitudes towards healthy eating, which have both been linked to healthier food choices and better diet quality ${ }^{(25-28)}$. Furthermore, the healthiness of meals relative to the amount of time spent on preparation may depend on the meal occasion. One study found that spending more than 5 min on preparation was associated with higher fat and saturated fat intakes compared with spending less than 5 min for breakfast and lunch meals but not for dinner ${ }^{(29)}$. Spending less than 5 min on preparation was also associated with higher intakes of Fe, whole grains and dairy foods at breakfast but lower intake of Fe at lunch ${ }^{(29)}$. This could suggest that the study participants were consuming quick meals such as milk and cereals fortified with nutrients such as Fe for breakfast; thus highlighting that not all convenience or quick meals are equal in terms of nutritional content. However, that study was limited in that it only included women aged 40-60 years and did not adjust for socio-economic factors ${ }^{(29)}$. This may be important as a systematic review examining links between food costs and socio-economic inequalities in diet and health concluded that healthy and culturally acceptable diets were more expensive and less affordable for low-income groups ${ }^{(30)}$. That paper placed emphasis on the importance of social and cultural norms because while some healthy food items such as organ meats, lentils and beans are relatively cheap, some people may find them unappealing or lack the necessary skills to prepare such foods ${ }^{(30)}$. Thus, to summarise, simply spending time preparing meals at home may not always result in a healthier diet as other factors related to socio-economic status, individual attitudes and home-food management skills are likely to influence diet quality.

Nevertheless, time availability could be a key driver of food choices, such as preparing home-cooked food, and time-related issues, such as time constraints or perceived time pressure, may act as barriers to healthy eating. A potential source of time-related issues for adults in employment is long work hours. However, studies on the relationship between work hours and diet quality have not consistently found one. In several studies it was the most commonly reported cause of perceived time pressure against eating a healthy diet among Australian women ${ }^{(12)}$, a contributing factor to time scarcity among low-waged mothers in the USA ${ }^{(6)}$ and a key time-related barrier to healthy eating among young American adults ${ }^{(8)}$. Another study found that mothers in full-time employment reported less time spent preparing meals and fewer family meals, as well as lower fruit and vegetable intake than both mothers in part-time work and mothers not in employment, after adjusting for sociodemographic factors including income and education ${ }^{(31)}$. Similarly, cluster analysis identified single parents and those working long hours and overtime to be more likely to report consuming foods prepared away from home (e.g. restaurant meals, takeaways and ready-made foods), as well as engage in other food strategies including 'grabbing' quick foods, missing meals and overcompensating for missed meals by eating more at the next meal ${ }^{(32)}$. This may have had a negative impact on diet quality as these parents had lower Healthy Eating Index scores, indicating poorer compliance with US dietary guidelines, compared with those who reported greater frequency of home-cooked family meals ${ }^{(32)}$. However, this cluster characterised by greater cooking frequency tended to include more married fathers with spouses who were not in employment or working part-time ${ }^{(32)}$. This highlights the importance of considering household composition as those working greater hours may be able to consume healthier home-cooked meals if another household member has greater responsibility for food. However, not all studies have found an association between hours worked and dietary outcomes and behaviour. Escoto et al. found no significant association between work hours and fast-food intake among young US adults ${ }^{(8)}$. Analysis of the Australian Health Survey (2011-2013) found fibre, vitamin C, Ca and Mg intakes to be lower among mothers not in employment compared with those in employment ${ }^{(33)}$. The reason for the association remains poorly understood and requires investigation.

In 2018, $75.6 \%$ of 16-64-year-olds in the UK were reported to be in full or part-time paid employment ${ }^{(34)}$. As the routines of many adults are likely to revolve around employment, more time spent at work may compromise the ability to achieve a healthy diet. The aim of the present study was to investigate whether number of hours worked in paid employment was associated with diet quality, frequency of eating out and consuming takeaways among UK adults.

\section{Methods}

Data from the UK National Diet and Nutrition Survey (NDNS) 2008-2014 were used for the present study ${ }^{(35,36)}$. The NDNS is a cross-sectional survey covering a nationally representative sample of the UK population aged 1.5 years or over living in private households. Data about dietary intakes were collected using four-day food diaries. Sociodemographic and information about eating habits 
Table 1 Scoring criteria for each food and nutrient component of the Diet Quality Index

\begin{tabular}{|c|c|c|c|}
\hline Food/nutrient & Target & Score & Rationale \\
\hline Fruit and vegetables & 5 portions/d & $\begin{array}{l}\text { Sliding score from } 0 \text { ( } 0 \text { portion }) \\
\text { to a maximum of } 10 \\
\text { ( } \geq 5 \text { portions) }\end{array}$ & Public Health England: Eatwell Guide ${ }^{(64)}$ \\
\hline Oily and white fish & $\begin{array}{l}2 \text { ( } 140 \mathrm{~g}) \text { portions } \\
\text { (one portion should } \\
\text { be oily fish) }\end{array}$ & $\begin{array}{l}\text { Sliding score from } 0(0 \mathrm{~g}) \text { to a } \\
\text { maximum of } 10(\geq 280 \mathrm{~g})\end{array}$ & $\begin{array}{l}\text { Scientific Advisory Committee on Nutrition: } \\
\text { Advice on Fish Consumption: Benefits and } \\
\text { Risks }^{(65)}\end{array}$ \\
\hline Red meat & $\leq 70 \mathrm{~g} / \mathrm{d}$ & $\begin{array}{l}>70 \mathrm{~g}=0 \\
\leq 70 \mathrm{~g}=5\end{array}$ & Public Health England: Eatwell Guide ${ }^{(64)}$ \\
\hline Processed meat & $0 \mathrm{~g} / \mathrm{d}$ & $\begin{array}{l}>0 \mathrm{~g}=0 \\
0 \mathrm{~g}=5\end{array}$ & Public Health England: Eatwell Guide ${ }^{(64)}$ \\
\hline NSP & $23 \mathrm{~g} / \mathrm{d}$ & $\begin{array}{l}\text { Sliding score from } 0(0 \mathrm{~g}) \text { to a } \\
\text { maximum of } 10(\geq 23 \mathrm{~g})\end{array}$ & $\begin{array}{l}\text { Scientific Advisory Committee on Nutrition: } \\
\text { Carbohydrates and Health }\end{array}$ \\
\hline Non-milk extrinsic sugars & $\leq 5 \%$ of food energy & $\begin{array}{l}>5 \%=0 \\
\leq 5 \%=10\end{array}$ & $\begin{array}{l}\text { Scientific Advisory Committee on Nutrition: } \\
\text { Carbohydrates and Health }{ }^{(66)}\end{array}$ \\
\hline Total fat & $\leq 35 \%$ of food energy & $\begin{array}{l}>35 \%=0 \\
\leq 35 \%=10\end{array}$ & $\begin{array}{l}\text { Committee on Medical Aspects of Food } \\
\text { Policy: Dietary Reference Values for Food } \\
\text { Energy and Nutrients for the United } \\
\text { Kingdom }^{(67)}\end{array}$ \\
\hline Saturated fat & $\leq 11 \%$ of food energy & $\begin{array}{l}>11 \%=0 \\
\leq 11 \%=10\end{array}$ & $\begin{array}{l}\text { Committee on Medical Aspects of Food } \\
\text { Policy: Dietary Reference Values for Food } \\
\text { Energy and Nutrients for the United } \\
\text { Kingdom }^{(67)}\end{array}$ \\
\hline Alcohol & $\leq 5 \%$ of total energy & $\begin{array}{l}>5 \%=0 \\
\leq 5 \%=5\end{array}$ & Adapted from the Scottish Dietary Targets ${ }^{(37)}$ \\
\hline
\end{tabular}

were collected during face-to-face computer-assisted personal interviews.

\section{Sample}

A total of 9374 people participated in the NDNS programme from 2008 to 2014. A minimum age limit of 19 years and an upper age limit of 64 years were applied in the present study. Only adults in full or part-time employment and not in education were included in the analyses. Participants aged under 19 years made up $49.5 \%$ of the total sample and those over age of 64 years made up only $3.2 \%$ of people in employment. Those over the upper age limit were excluded to account for the retirement age in the UK being 65 years at the time of the survey. Adults who reported working less than $1 \mathrm{~h} /$ week were also excluded. This gave a sample of 2154 adults included in the study. Cases that contained missing data ( $n$ 256) for any of the variables were excluded from the analyses.

\section{Variables}

Data for hours worked were based on self-reported number of hours worked during a normal week in a regular job (i.e. not occasional jobs). The original NDNS variable for hours worked was capped at $97 \mathrm{~h}$ and participants who worked over this maximum limit were reported as ' $97 \mathrm{~h}$ or more'. For the current analysis, the maximum threshold for hours worked was reduced from 97 to $70 \mathrm{~h}$ because only $0.5 \%$ of the sample worked over $70 \mathrm{~h}$.

Sociodemographic factors of interest include sex, age, equivalised household income, household composition and household food role. Equivalised household income, which considers household size and composition, was used to represent socio-economic status and treated on a continuous scale. Household composition was split into three categories which included single-person households, multi-person households without children and households with children. Household food role was dichotomised into being and not being the main food provider, which was defined in the NDNS as the person in the household with main responsibility for food shopping and preparation.

A Diet Quality Index (DQI), adapted from one previously designed by Armstrong et al. ${ }^{(37)}$, was calculated based on UK dietary recommendations for five food groups and four nutrients (see Table 1). Following the system used by Armstrong et $a l^{(37)}$, scores assigned to each DQI component were determined by the extent to which the corresponding dietary target was met. Scores for fruit and vegetables, oily and white fish, and NSP were on a sliding scale from a minimum of 0 to a maximum of 10 . The score for fruit and vegetables was derived by dividing the number of portions per day reported by the recommended 5 portions and multiplying by 10. For NSP, reported intake was divided by the recommended $23 \mathrm{~g}$ and multiplied by 10 . These scores were capped at a maximum of 10 . The score for oily and white fish was based on the recommendation of at least one of the two portions of fish consumed weekly being oily ( $140 \mathrm{~g})$. First, the weight of oily and white fish consumed was divided by $140 \mathrm{~g}$ and then multiplied by 10 and 5 , respectively. The sum of oily and white fish scores was also capped at a maximum of 10 . The remaining six DQI components (non-milk extrinsic sugars, total fat, saturated fat, red meat, processed meat and alcohol) were assigned a binary score of 0 for targets that were not met, and 5 or 10 for targets that were met. The sum of all scores was converted into a percentage of the maximum score of 75 . A higher DQI 
percentage score reflects a diet that is closer to meeting dietary targets and therefore better diet quality. The individual foods and nutrients making up the DQI were then assessed separately.

The original NDNS variable for frequency of eating out was based on a multiple-choice question which asked participants for their estimated frequency of meals eaten in a restaurant or café. The original NDNS variable for frequency of consuming takeaways was based on a multiple-choice question which asked participants for their estimated frequency of meals purchased away from home but eaten in their homes including pizza, fish and chips, Indian and Chinese food, burgers and kebabs. In both cases, meals were considered to be something more than a beverage or a bag of chips. The multiple-choice responses included: ' 5 or more times per week', '3-4 times per week, '1-2 times per week', '1-2 times per month' and 'rarely or never'. For the current analysis, original variables for both frequency of eating out and consuming takeaways were collapsed to 'at least once per week', 'at least once per month' and 'rarely or never' due to the lower frequency rates in the weekly sub-categories.

\section{Statistical analysis}

Preliminary bivariate analysis was conducted to test associations between hours worked and sociodemographic factors, DQI, selected foods and nutrients, frequency of eating out and consuming takeaways using independent-samples $t$ tests, Pearson correlation and one-way ANOVA with Scheffé post hoc tests. For the main analysis, separate linear regression models were used to assess associations of hours worked with DQI score and selected foods and nutrients (Table 1). Separate ordinal logistic regression models were used to assess associations of hours worked with frequency of eating out and consuming takeaways. All models were adjusted for sex, age, equivalised household income, household composition and household food role. The reference category for sex was female, for household composition was households with children, for household food role was not being the main food provider. Models for fruit and vegetables, oily and white fish, red meat (including beef, lamb, pork and offal), processed meat (including processed red meat, sausages and burgers) and NSP were adjusted for food energy intake. Interaction terms between hours worked and each sociodemographic factor were then added to the models. Lastly, a quadratic term was added to all models to test for non-linear relationships. Values were considered statistically significant if $P<0 \cdot 05$. All analyses were conducted using the statistical software package IBM SPSS Statistics version 24 .

\section{Results}

\section{Sample characteristics}

The median age of the sample was 42 years with an interquartile range of 33-50 years. The sample included a
Table 2 Mean Diet Quality Index (DQI) score and reported intakes of selected foods and nutrients among adults ( $n$ 2154) aged 19-64 years in employment, UK National Diet and Nutrition Survey (2008-2014)

\begin{tabular}{|c|c|c|}
\hline Diet quality measure & Mean & $95 \% \mathrm{Cl}$ \\
\hline DQI score (\%) & 41.9 & $41 \cdot 2,42 \cdot 5$ \\
\hline Fruit and vegetables (portions/d) & $4 \cdot 1$ & $4 \cdot 0,4 \cdot 2$ \\
\hline Oily and white fish $(\mathrm{g} / \mathrm{d})$ & $21 \cdot 1$ & $19 \cdot 7,22 \cdot 4$ \\
\hline Red meat $(\mathrm{g} / \mathrm{d})$ & 34.0 & $32 \cdot 4,35.5$ \\
\hline Processed meat $(\mathrm{g} / \mathrm{d})$ & $36 \cdot 3$ & $34.7,37.9$ \\
\hline $\operatorname{NSP}(g / d)$ & $13 \cdot 9$ & $13 \cdot 7,14 \cdot 1$ \\
\hline Total fat ( $\%$ of food energy) & 34.7 & $34.4,35 \cdot 0$ \\
\hline Saturated fat ( $\%$ of food energy) & $12 \cdot 7$ & $12 \cdot 6,12 \cdot 9$ \\
\hline $\begin{array}{l}\text { Non-milk extrinsic sugars } \\
\text { (\% of food energy) }\end{array}$ & $11 \cdot 8$ & $11 \cdot 5,12 \cdot 0$ \\
\hline Alcohol (\% of total energy) & 4.9 & $4 \cdot 6,5 \cdot 2$ \\
\hline
\end{tabular}

slightly higher proportion of women (54.7\%) than men and more main food providers $(72.5 \%)$ than non-main food providers. Within the sample, $46.0 \%$ lived in households with children, $36 \cdot 1 \%$ lived in multi-person households without children and $17.9 \%$ lived alone. In terms of education, $31.1 \%$ had attained a degree or higher, $34.4 \%$ had completed further education (below degree), $21.6 \%$ had GCSE (General Certificate of Secondary Education) or equivalent and $9.8 \%$ had no qualifications. The median annual equivalised household income was $£ 32357$ ranging from $£ 1087$ to $£ 184425$, with an interquartile range of $£ 20491-£ 47500$.

The mean number of hours worked per week was $36 \cdot 1$ (95\% CI 35.6, 36.6). The unadjusted analysis showed that hours worked was associated with being male $\left(t_{(2152)}=20 \cdot 837, P<0 \cdot 001\right)$, not being the main food provider $\left(t_{(1253)}=-13.871, P<0.001\right)$ and higher equivalised household income $(r=0 \cdot 278, P<0 \cdot 001)$. Hours worked was associated household composition $\left(F_{(2,2151)}=27 \cdot 153, P<0 \cdot 001\right)$ with adults living with children working significantly fewer

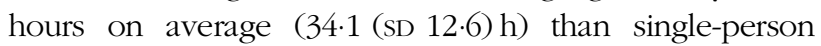
households (38.6 (sD 10.7) h, $P<0.001$ ) and multi-person households without children (37.3 (sD 10.8) h, $P<0.001$ ). No significant difference in hours worked was seen between single-person households and multi-person households without children $(P=0 \cdot 203)$. Hours worked was not significantly associated with age $(r=-0.012, P=0.563)$.

Mean intakes of fruit and vegetables, NSP and oily and white fish were below recommendations set for the UK, and the mean intakes of processed meat, saturated fat and non-milk extrinsic sugars were over the maximum recommendations (Table 2). Mean intakes of red meat, total fat and alcohol were below the maximum recommended upper limit. The mean DQI score of the sample was 41.9 (95\% CI 41.2, 42.5) \% ranging from 5.9 to $89.7 \%$.

\section{Association between bours worked and diet quality}

Before adjusting for sociodemographic factors, hours worked was negatively associated with DQI and positively associated 
Table 3 Unadjusted and adjusted associations between hours worked, Diet Quality Index (DQI) score and selected foods and nutrients among adults ( $n$ 2154) aged 19-64 years in employment, UK National Diet and Nutrition Survey (2008-2014)

\begin{tabular}{|c|c|c|c|c|c|}
\hline \multirow[b]{2}{*}{ Diet quality measure } & \multicolumn{2}{|c|}{ Unadjusted analysis } & \multicolumn{3}{|c|}{ Adjusted analysis* } \\
\hline & Coefficient & $P$ & Coefficient & $95 \% \mathrm{Cl}$ & $P$ \\
\hline DQI score (\%) & -0.053 & 0.013 & -0.049 & $-0.115,0.016$ & 0.138 \\
\hline Fruit and vegetables $(\mathrm{g} / \mathrm{d})$ & 0.037 & 0.085 & 0.029 & $-0.645,0.703$ & 0.933 \\
\hline Oily and white fish $(\mathrm{g} / \mathrm{d})$ & 0.045 & 0.036 & -0.003 & $-0.135,0.129$ & 0.967 \\
\hline Red meat $(\mathrm{g} / \mathrm{d})$ & $0 \cdot 121$ & $<0.001$ & 0.168 & $0.022,0.315$ & 0.024 \\
\hline Processed meat $(\mathrm{g} / \mathrm{d})$ & $0 \cdot 130$ & $<0.001$ & 0.143 & $-3.646 \times 10^{-5}, 0.286$ & 0.050 \\
\hline $\operatorname{NSP}(g / d)$ & 0.091 & $<0.001$ & -0.012 & $-0.029,0.004$ & 0.131 \\
\hline Total fat (\% of food energy) & 0.035 & 0.108 & $6.878 \times 10^{-5}$ & $-0.026,0.026$ & 0.996 \\
\hline Saturated fat (\% of food energy) & 0.015 & 0.475 & -0.001 & $-0.014,0.013$ & 0.902 \\
\hline Non-milk extrinsic sugars ( $\%$ of food energy) & 0.052 & 0.016 & 0.014 & $-0.011,0.039$ & 0.277 \\
\hline Alcohol (\% of total energy) & 0.137 & $<0.001$ & 0.055 & $0.028,0.082$ & $<0.001$ \\
\hline
\end{tabular}

${ }^{*}$ All models adjusted for age, sex, equivalised household income, household composition and household food role.

Table 4 Significant interaction terms derived from linear regression analysis between hours worked and sociodemographic factors in association with selected foods and nutrients among adults ( $n$ 2154) aged 19-64 years in employment, UK National Diet and Nutrition Survey (2008-2014)

\begin{tabular}{|c|c|c|c|c|}
\hline Dependent variable & Interaction term* & Coefficient & $95 \% \mathrm{Cl}$ & $P$ \\
\hline \multirow[t]{3}{*}{ NSP $(g / d)$} & Hours worked $\times$ household composition & & & 0.014 \\
\hline & Hours worked $\times$ multi-person household without children & 0.041 & $0.006,0.075$ & 0.021 \\
\hline & Hours worked $\times$ single household & -0.018 & $-0.067,0.030$ & 0.460 \\
\hline \multirow[t]{2}{*}{ Total fat ( $\%$ of food energy) } & Hours worked $\times$ household composition & & & 0.044 \\
\hline & $\begin{array}{l}\text { Hours worked } \times \text { multi-person household without children } \\
\text { Hours worked } \times \text { single household }\end{array}$ & $\begin{array}{l}-0.071 \\
-0.036\end{array}$ & $\begin{array}{l}-0.126,0.015 \\
-0.113,0.042\end{array}$ & $\begin{array}{l}0.013 \\
0.364\end{array}$ \\
\hline \multirow[t]{2}{*}{ Saturated fat (\% of food energy) } & Hours worked $\times$ household composition & & & 0.005 \\
\hline & $\begin{array}{l}\text { Hours worked } \times \text { multi-person household without children } \\
\text { Hours worked } \times \text { single household }\end{array}$ & $\begin{array}{l}-0.047 \\
-0.009\end{array}$ & $\begin{array}{l}-0.076,-0.018 \\
-0.049,0.032\end{array}$ & $\begin{array}{l}0.002 \\
0.680\end{array}$ \\
\hline Fruit and vegetables $(\mathrm{g} / \mathrm{d})$ & Hours worked $\times$ age & -0.063 & $-0.119,-0.006$ & 0.031 \\
\hline Red meat $(\mathrm{g} / \mathrm{d})$ & Hours worked $\times$ age & 0.017 & $0.005,0.029$ & 0.007 \\
\hline
\end{tabular}

${ }^{*}$ Reference category for sex was female, and for household composition was households with children.

with NSP, non-milk extrinsic sugars, oily and white fish, red meat, processed meat and alcohol intakes (Table 3). After adjustment, only the positive associations between hours worked and red meat, processed meat and alcohol intakes remained significant at the $95 \%$ level (Table 3 ).

As shown in Table 4, significant interactions between hours worked and household composition were found showing that among adults working more hours, those living with children had lower NSP intake but higher total fat and saturated fat intakes than those from multi-person households without children. No significant differences were found between households with children and single-person households. Further interactions between hours worked and age showed that among those working more hours, older adults had lower intake of fruit and vegetables and higher intake of red meat than younger adults. A quadratic term was added to all models and found to be insignificant, implying that there were no indications of non-linear relationships.

\section{Association between bours worked and frequency of eating out}

Before adjusting for sociodemographic factors, there were significant differences in hours worked by frequency of eating out $\left(F_{(2,2151)}=11.483, P<0.001\right)$, where adults who ate out at least once per week worked more hours (38.0 (SD 12.3) h) than those who ate out at least once per month $(35.6$ (SD 11.4) h, $P=0.001)$ and those who rarely or never ate out $(34.8(\mathrm{SD} 11.5) \mathrm{h}, P<0.001)$. After adjusting for sociodemographic factors, hours worked was not significantly associated with frequency of eating out (estimate $=-0.003$ (95\% CI $-0.011,-0.005)$, $P=0 \cdot 418$ ). A significant interaction between hours worked and sex shows that with more hours worked, men were less likely to eat out weekly or monthly than rarely or never compared with women (estimate $=-0.021 \quad(95 \%$ CI -0.041, -0.001), $P=0.039)$.

\section{Association between bours worked and frequency of consuming takeaways}

No significant association was found between hours worked and frequency of consuming takeaways before $\left(F_{(2,2150)}=0.300, \quad P=0.741\right)$ and after (estimate $=-0.001$ (95\% CI $-0.007,-0.008), P=0.881$ ) adjusting for sociodemographic factors. A significant interaction between hours worked and household composition shows that with more hours worked, those living in multi-person households without children were more likely to have takeaways weekly or 
monthly than rarely or never compared with households with children (estimate $=-0.018(95 \%$ CI 0.001, 0.035), $P=0.038$ ).

\section{Discussion}

In summary, the present study found no association between hours worked and DQI score after adjusting for sociodemographic factors, which suggests that working more hours did not significantly impact overall diet quality. However, significant interactions were found with differences in nutrient intake between subgroups within this population, with the most notable being among those working longer hours from different household compositions.

While hours worked was not linked to overall diet quality, further analysis of selected foods and nutrients showed that adults working longer hours had a higher proportion of total energy intake from alcohol than those working fewer hours. A systematic review and meta-analysis also found this positive correlation and concluded that individuals working over $48 \mathrm{~h} /$ week were more likely to have high levels of alcohol intake that were potentially detrimental to health ${ }^{(38)}$. The health implications of alcohol are complex, with longitudinal data demonstrating a U-shaped relationship where non-drinkers and heavy drinkers have higher mortality rates than moderate drinkers ${ }^{(39-43)}$. Although the average population intake in the present study met recommendations, adults working longer hours were found to exceed the maximum limit set which could put them at greater risk of negative health outcomes.

In addition, adults working greater hours were found to have higher intakes of both red and processed meat than those working fewer hours, even after adjusting for factors that have been shown to influence consumption including sex $^{(44-46)}$ and income ${ }^{(47,48)}$. This relationship may be dependent on age, which showed a significant interaction with hours worked, suggesting the positive association between hours worked and red meat intake was stronger in older adults than younger adults. Understanding drivers of red and processed meat intakes and how these might be related to working longer hours is important due to the negative implications of increased consumption for both health $^{(49,50)}$ and environmental sustainability ${ }^{(51)}$.

Hours worked did not show associations with the majority of the selected foods and nutrients included in the current analysis. In particular, hours worked was not linked to other foods including fruit and vegetables and oily and white fish. This is consistent with a cross-sectional Australian study that also found no link between working hours and intake of a wider range of dietary components, including vitamins and minerals, among women in employment ${ }^{(33)}$. One possible explanation is that the number of hours worked may not necessarily correspond to the amount of free time available or perceived time pressure, or desire to eat a healthy diet. Hours worked is not the possible driver of food choices that people make. Preferences for different types of foods, taste, and other social and economic issues are other important determinants.

The difference between time constraint and perceived time pressure is important. A US study of young adults found no significant association between number of hours worked and perceived time constraints ${ }^{(52)}$. This potentially highlights the limitations in exploring the direct link between time availability and diet quality as the perception of time available to carry out tasks is likely to differ between individuals. Perceived time pressure may also only become problematic after a certain threshold such as exceeding the standard full-time hours. For example, working over $40 \mathrm{~h} /$ week was significantly associated with time-related barriers to healthy eating and dietary intake among young adults ${ }^{(8)}$. These time-related barriers include beliefs that healthy eating took too much time and being too rushed in the morning to eat a healthy breakfast among men, and not having time to think about healthy eating and eating on the run among women. This could have adverse effects on dietary intake as women working over $40 \mathrm{~h}$ /week were less likely to report consuming five portions of fruit and vegetables daily than women working fewer hours ${ }^{(8)}$. Although the present study found no significant association between hours worked and diet quality within the overall sample, there were significant differences between subgroups. This may reflect varying levels of perceived time pressure by participants that could be a better predictor of dietary behaviour and outcome.

Past studies have identified quickness, being too busy to $\operatorname{cook}^{(53)}$, the need to reduce time and effort for meals, and to manage stress and fatigue ${ }^{(11)}$ as common reasons for purchasing convenience foods such as fast foods and takeaways. However, the present study found no significant association between hours worked and frequency of eating out or consuming takeaways, which suggests that adults working longer hours did not eat out or have takeaways more frequently than adults working fewer hours. Similarly, Escoto et al. found no significant association between work hours and consumption of fast foods ${ }^{(8)}$. Thus, although time and speed are important motivators for consuming food prepared away from home, this may not directly correlate with time availability or constraints stemming from hours worked. Instead, perceived time pressure may be a better predictor as a study found that adults who reported medium to high levels of perceived time pressure were more likely to consume fast foods and ultra-processed foods including ready meals compared with those reporting low time pressure ${ }^{(13)}$. Lavelle et al. also found participants attributed their use of convenience foods in cooking to feelings of lacking time during the work week, while citing employment to be a big cause of time pressure $^{(54)}$. Participants also reported not having energy and motivation to cook at home, which necessitated the consumption of takeaways meals. This further highlights the potential role of perceived time availability and pressure in dietary behaviour and outcome that may be influenced by the number of hours worked. A reason for 
not seeing an association in the current study may be due to the category being collapsed into 'at least once a week or more' (owing to the small number of people consuming takeaways more than once weekly in this category). It was therefore not possible to differentiate between people who may consume takeaways at the end of a week as a 'treat' from those who may consume them to save time due to regularly working longer hours.

Living with children may be a particularly pertinent factor influencing the perception of time pressure. The present study showed greater working hours combined with living with children to be associated with lower fibre, but higher total fat and saturated fat, intakes compared with multi-person households without children. Parents and carers have been the large focus of past qualitative studies exploring the relationship between employment, time and food choice ${ }^{(6,11,55,56)}$. In addition to working hours and job conditions, responsibility for children and other family members have been cited as key sources of time pressure ${ }^{(11,12,54)}$. The combined demands from both work and home may further exacerbate the ability to maintain a healthy diet as a recent study of parents reported lacking time and energy to make healthy food choices, enjoy food and cook for their families ${ }^{(11)}$. Another US study found experiences of time scarcity were widespread among low-waged mothers in employment, with many feeling unable to provide family meals that matched their ideals for healthy eating due to being too tired or not having enough time to cook after work ${ }^{(6)}$. In these cases, mothers would opt for ready-made foods or purchase something quick on their way home from work ${ }^{(6)}$, which could be less healthy than preparing their own meals at home. Contrary to this, the present study did not find any significant interactions to suggest adults who worked more hours and lived with children ate out or had takeaways any more frequently. Thus, the poorer nutrient intakes identified in this subgroup may be the result of other food strategies used, which may not be in response to time constraints ${ }^{(6,7,10)}$. It is, however, important to note that the present study provides information only on whether participants lived with children rather than if they were responsible for childcare.

Lastly, it may be important to consider household composition as the present study found that with more hours worked, adults living in multi-person households without children were more likely to have takeaways frequently than those living with children. Interestingly, with more hours worked, adults living in multi-person households without children also had higher-quality diets compared with those living with children. This suggests that the diets of those living with others but without children were still better than the diets of those living with children despite consuming takeaways more frequently. Meanwhile, no significant differences were seen between adults living with children and those living alone. Devine et al. highlighted the potential benefits of living with others as participants reported receiving encouragement from other household members to eat healthier foods such as fruits and vegetables, as well as having a greater variety of meals on a more regular basis since moving in with others ${ }^{(57)}$. The social aspect of eating was a key theme identified in another study which found that women were more likely to prepare special or luxurious meals involving meat and fish when eating with others ${ }^{(58)}$. By contrast, these women were found to simplify their food preparation when eating alone by having fewer cooked meals and opting for cold foods such as sandwiches ${ }^{(58)}$. Lone-eating habits could have a negative impact on overall diet quality as other studies have found poorer overall adherence to dietary recommendations for foods and nutrients including fruit and vegetables, fish, meat, fat, saturated fat, $\mathrm{Na}$, vitamins and minerals ${ }^{(59-63)}$. Differences in dietary behaviour and quality by household composition could therefore be further exacerbated by increasing number of hours worked where free time becomes scarce.

\section{Strengths and limitations}

A strength of the present study is the large sample size that is representative of the UK population. This DQI scoring system provides an overview of how closely an overall diet conforms to the UK dietary recommendations, but is limited to measuring diet quality based on a small range of foods and nutrients. The DQI is also limited by the dietary data that were collected using self-reported food diaries over four days within a week. As fish recommendations are set as weekly targets, this may not have been captured over only four days. Lastly, the NDNS does not collect information regarding household dynamics and roles which could be useful as the link between hours worked and food choice may differ, for example, by whether the participant may have other time commitments such as being a care provider. Time constraints due to hours worked may not be the main driver or barrier to eating a healthy diet. There are other factors such as food preferences, likes, dislikes of foods and economic constraints which will influence the food choices people make and these will vary between people. These are important considerations to be included in future studies.

\section{Conclusion}

The present study found no associations between hours worked and DQI, frequency of eating out or consuming takeaways among a sample of adults in employment in the UK. Although working hours did not appear to be a direct factor driving poor dietary intake, certain components positively correlated with hours worked (i.e. red meat, processed meat and alcohol) may require attention since these foods have been associated with increased risk to health. Focusing on food prepared outside the household among people who work longer hours may not be the most efficient way to improve diet quality due to a lack of association found in the present study. This suggests that 
efforts to improve dietary intakes need to be at all levels, both with food prepared and consumed in the home and outside the home. This applies to the whole population, not just those working long hours. However, household composition, particularly living with children, may be important as adults working longer hours had poorer nutrient intakes if they lived with children. This could reflect additional time constraints or feelings of time pressure around childcare. Further investigation is needed to understand whether the relationship between time constraints, food practices and diet quality among adults in employment is influenced by household composition, or whether other factors driving food choice are more important.

\section{Acknowledgements}

Acknowledgements: The authors thank Altea LorenzoArribas for assistance with the statistical analysis. Financial support: This work was supported by the Scottish Government Rural and Environment Science and Analytical Services (RESAS) division. RESAS had no role in the design, analysis or writing of this article. Conflict of interest: The authors declare that they have no conflicts of interest. Authorship: L.S., J.I.M. and T.C. were responsible for formulating the research questions and L.S. was responsible for analysing the data. G.W.H. provided statistical advice. L.S., J.I.M. and T.C. contributed to the preparation of the manuscript. Ethics of human subject participation: Not applicable.

\section{References}

1. Trichopoulou A, Costacou T, Bamia C et al. (2003) Adherence to a Mediterranean diet and survival in a Greek population. N Engl J Med 348, 2599-2608.

2. McCullough ML, Feskanich D, Stampfer MJ et al. (2002) Diet quality and major chronic disease risk in men and women: moving toward improved dietary guidance. Am J Clin Nutr 76, 1261-1271.

3. Chiuve SE, Fung TT, Rimm EB et al. (2012) Alternative dietary indices both strongly predict risk of chronic disease. $\mathrm{J} \mathrm{Nutr}$ 142, 1009-1018.

4. Furst T, Connors M, Bisogni CA et al. (1996) Food choice: a conceptual model of the process. Appetite 26, 247-265.

5. Sobal J \& Bisogni CA (2009) Constructing food choice decisions. Ann Behav Med 38, 37-46.

6. Jabs J, Devine CM, Bisogni CA et al. (2007) Trying to find the quickest way: employed mothers' constructions of time for food. J Nutr Educ Behav 39, 18-25.

7. Bava CM, Jaeger SR \& Park J (2008) Constraints upon food provisioning practices in 'busy' women's lives: trade-offs which demand convenience. Appetite 50, 486-498.

8. Escoto KH, Laska MN, Larson N et al. (2012) Work hours and perceived time barriers to healthful eating among young adults. Am J Health Behav 36, 786-796.

9. Larson NI, Perry CL, Story M et al. (2006) Food preparation by young adults is associated with better diet quality. J Am Diet Assoc 106, 2001-2007.
10. Horning ML, Fulkerson JA, Friend SE et al. (2017) Reasons parents buy prepackaged, processed meals: it is more complicated than 'I don't have time'. J Nutr Educ Behav 49, 60-66.

11. Devine CM, Jastran M, Jabs J et al. (2006) 'A lot of sacrifices': work-family spillover and the food choice coping strategies of low-wage employed parents. Soc Sci Med 63, 2591-2603.

12. Welch N, McNaughton SA, Hunter W et al. (2009) Is the perception of time pressure a barrier to healthy eating and physical activity among women? Public Health Nutr 12, 888-895.

13. Djupegot IL, Nenseth CB, Bere E et al. (2017) The association between time scarcity, sociodemographic correlates and consumption of ultra-processed foods among parents in Norway: a cross-sectional study. BMC Public Health 17, 447.

14. Seguin RA, Aggarwal A, Vermeylen F et al. (2016) Consumption frequency of foods away from home linked with higher body mass index and lower fruit and vegetable intake among adults: a cross-sectional study. J Environ Public Health 2016, 3074241.

15. Lachat C, Nago E, Verstraeten R et al. (2012) Eating out of home and its association with dietary intake: a systematic review of the evidence. Obes Rev 13, 329-346.

16. Goffe L, Rushton S, White M et al. (2017) Relationship between mean daily energy intake and frequency of consumption of out-of-home meals in the UK National Diet and Nutrition Survey. Int J Behav Nutr Phys Act 14, 131.

17. Clemens LH, Slawson DL \& Klesges RC (1999) The effect of eating out on quality of diet in premenopausal women. $J \mathrm{Am}$ Diet Assoc 99, 442-444.

18. Pereira MA, Kartashov AI, Ebbeling CB et al. (2005) Fast-food habits, weight gain, and insulin resistance (the CARDIA Study): 15-year prospective analysis. Lancet 365, 36-42.

19. Penney TL, Jones NRV, Adams J et al. (2017) Utilization of away-from-home food establishments, dietary approaches to stop hypertension dietary pattern, and obesity. Am J Prev Med 53, e155-e163.

20. Jaworowska A, Blackham T, Davies IG et al. (2013) Nutritional challenges and health implications of takeaway and fast food. Nutr Rev 71, 310-318.

21. Monsivais P, Aggarwal A \& Drewnowski A (2014) Time spent on home food preparation and indicators of healthy eating. Am J Prev Med 47, 796-802.

22. Wolfson JA \& Bleich SN (2015) Is cooking at home associated with better diet quality or weight-loss intention? Public Health Nutr 18, 1397-1406.

23. Tumin R \& Anderson SE (2017) Television, home-cooked meals, and family meal frequency: associations with adult obesity. J Acad Nutr Diet 117, 937-945.

24. Howard S, Adams J \& White M (2012) Nutritional content of supermarket ready meals and recipes by television chefs in the United Kingdom: cross sectional study. BMJ 345, e 7607 .

25. Aggarwal A, Monsivais P, Cook AJ et al. (2014) Positive attitude toward healthy eating predicts higher diet quality at all cost levels of supermarkets. J Acad Nutr Diet 114, 266-272.

26. Beydoun MA \& Wang Y (2008) How do socio-economic status, perceived economic barriers and nutritional benefits affect quality of dietary intake among US adults? Eur J Clin Nutr 62, 303-313.

27. Turrell G, Hewitt B, Patterson C et al. (2002) Socioeconomic differences in food purchasing behaviour and suggested implications for diet-related health promotion. J Hum Nutr Diet 15, 355-364.

28. Dammann KW \& Smith C (2009) Factors affecting low-income women's good choices and the perceived impact of dietary intake and socioeconomic status on their health and weight. J Nutr Educ Behav 41, 242-253. 
29. Chu YL, Addo OY, Perry CD et al. (2012) Time spent in home meal preparation affects energy and food group intakes among midlife women. Appetite 58, 438-443.

30. Darmon N, Drewnowski A, James W et al. (2015) Contribution of food prices and diet cost to socioeconomic disparities in diet quality and health: a systematic review and analysis. Nutr Rev 73, 643-660.

31. Bauer KW, Hearst MO, Escoto K et al. (2012) Parental employment and work-family stress: associations with family food environments. Soc Sci Med 75, 496-504.

32. Blake CE, Wethington E, Farrell TJ et al. (2011) Behavioral contexts, food-choice coping strategies, and dietary quality of a multiethnic sample of employed parents. J Am Diet Assoc 111, 401-407.

33. Miller J, Chan L, Mehta K et al. (2016) Dietary intake of working women with children does not appear to be influenced by hours of employment: a secondary analysis of the Australian Health Survey (2011-2013). Appetite 105, 106-113.

34. Office for National Statistics (2018) UK labour market: May 2018. https://www.ons.gov.uk/employmentandlabourmarket/ peopleinwork/employmentandemployeetypes/bulletins/ uklabourmarket/may2018 (accessed December 2018).

35. Bates B, Lennox A, Prentice A et al. (2014) National Diet and Nutrition Survey Results from Years 1, 2, 3 and 4 (combined) of the Rolling Programme (2008/2009-2011/2012). London: Public Health England.

36. Bates B, Cox L, Nicholson S et al. (2016) National Diet and Nutrition Survey Results from Years 5 and 6 (combined) of the Rolling Programme (2012/2013-2013/2014). London: Public Health England.

37. Armstrong K, Sherriff A, Wrieden WL et al. (2009) Deriving and Interpreting Dietary Patterns in the Scottish Diet: Further Analysis of the Scottish Health Survey and Expenditure and Food Survey. Aberdeen: Foods Standards Scotland.

38. Virtanen M, Jokela M, Nyberg ST et al. (2015) Long working hours and alcohol use: systematic review and meta-analysis of published studies and unpublished individual participant data. BMJ 350, g7772.

39. Shaper AG, Wannamethee G \& Walker M (1988) Alcohol and mortality in British men: explaining the U-shaped curve. Lancet 332, 1267-1273.

40. Marmot MG, Shipley MJ, Rose G et al. (1981) Alcohol and mortality: a U-shaped curve. Lancet 14, 580-583.

41. Xi B, Veeranki SP, Zhao M et al. (2017) Relationship of alcohol consumption to all-cause, cardiovascular, and cancer-related mortality in US adults. J Am Coll Cardiol 70, 913-922.

42. Gémes K, Janszky I, Ahnve S et al. (2016) Light-to-moderate drinking and incident heart failure - the Norwegian HUNT study. Int J Cardiol 203, 553-560.

43. Mukamal KJ, Chen CM, Rao SR et al. (2010) Alcohol consumption and cardiovascular mortality among US adults, 1987 to 2002. I Am Coll Cardiol 55, 1328-1335.

44. Sobal J (2005) Men, meat and marriage: models of masculinity. Food Foodways 13, 135-158.

45. Heinz B \& Lee R (1998) Getting down to the meat: the symbolic construction of meat consumption. Commun Stud 49, 86-99.

46. Kubberød E, Ueland $\varnothing$, Rødbotten M et al. (2002) Gender specific preferences and attitudes towards meat. Food Qual Prefer 13, 285-294.

47. Jeremiah LE (1982) A review of factors influencing consumption, selection and acceptability of meat purchases. J Consum Stud Home Econ 6, 137-154.
48. Delgado CL (2003) Rising consumption of meat and milk in developing countries has created a new food revolution. J Nutr 133, 3907-3910

49. Larsson SC \& Orsini N (2014) Red meat and processed meat consumption and all-cause mortality: a meta-analysis. $\mathrm{Am} \mathrm{J}$ Epidemiol 179, 282-289.

50. Pan A, Sun Q, Bernstein AM et al. (2012) Red meat consumption and mortality: results from 2 prospective cohort studies. Arch Intern Med 172, 555-563.

51. Hedenus F, Wirsenius S \& Johansson DJA (2014) The importance of reduced meat and dairy consumption for meeting stringent climate change targets. Clim Change 124, 79-91.

52. Pelletier JE \& Laska MN (2012) Balancing healthy meals and busy lives: associations between work, school, and family responsibilities and perceived time constraints among young adults. I Nutr Educ Behav 44, 481-489.

53. Rydell SA, Harnack LJ, Oakes JM et al. (2008) Why eat at fast-food restaurants: reported reasons among frequent consumers. J Am Diet Assoc 108, 2066-2070.

54. Lavelle F, McGowan L, Spence M et al. (2016) Barriers and facilitators to cooking from 'scratch' using basic or raw ingredients: a qualitative interview study. Appetite 107, 383-391.

55. Alm S \& Olsen SO (2017) Coping with time pressure and stress: consequences for families' food consumption. J Consum Policy 40, 105-123.

56. Devine CM, Connors MM, Sobal J et al. (2003) Sandwiching it in: spillover of work onto food choices and family roles in low- and moderate-income urban households. Soc Sci Med 56, 617-630.

57. Devine CM, Connors M, Bisogni CA et al. (1998) Life-course influences on fruit and vegetable trajectories: qualitative analysis of food choices. J Nutr Educ 30, 361-370.

58. Gustafsson K \& Sidenvall B (2002) Food-related health perceptions and food habits among older women. $J$ Adv Nurs 39, 164-173.

59. Dynesen AW, Haraldsdóttir J, Holm L et al. (2003) Sociodemographic differences in dietary habits described by food frequency questions - results from Denmark. Eur J Clin Nutr 57, 1586-1597.

60. Gerrior SA, Guthrie JF, Fox JJ et al. (1995) Differences in the dietary quality of adults living in single versus multiperson households. J Nutr Educ 27, 113-119.

61. Hunter W, McNaughton S, Crawford D et al. (2010) Does food planning mediate the association between living arrangements and fruit and vegetable consumption among women aged 40 years and older? Appetite 54, 533-537.

62. Conklin AI, Forouhi NG, Surtees P et al. (2014) Social relationships and healthful dietary behaviour: evidence from over-50s in the EPIC Cohort, UK. Soc Sci Med 100, 167-175.

63. Vinther JL, Conklin AI, Wareham NJ et al. (2016) Marital transitions and associated changes in fruit and vegetable intake: findings from the population-based prospective EPIC-Norfolk Cohort, UK. Soc Sci Med 157, 120-126.

64. Public Health England (2016) Eatwell Guide. https://assets. publishing.service.gov.uk/government/uploads/system/ uploads/attachment_data/file/528193/Eatwell_guide_colour. pdf (accessed December 2018).

65. Scientific Advisory Committee on Nutrition (2004) Advice on Fish Consumption: Benefits and Risks. London: The Stationery Office.

66. Scientific Advisory Committee on Nutrition (2015) Carbohydrates and Health. London: The Stationery Office.

67. Committee on Medical Aspects of Food Policy (1991) Dietary Reference Values for Food Energy and Nutrients for the United Kingdom. London: HMSO. 